УДК $615.322: 547.913$

\title{
ИЗУЧЕНИЕ КОМПОНЕНТНОГО СОСТАВА ЭФИРНОГО МАСЛА И МИНЕРАЛЬНОГО СОСТАВА ВОЛОДУШКИ ЗОЛОТИСТОЙ СИБИРСКОГО РЕГИОНА
}

\author{
() И.Д. Зыкова", А.А. Ефремов \\ Сибирский феедеральный университет, пр. Свободный, 79, Красноярск, \\ 660041 (Россия), e-mail: izykova@sfu-kras.ru
}

Методом хромато-масс-спектрометрии исследован компонентный состав эфирного масла володушки золотистой, полученного исчерпывающей гидропародистилляцией надземной части растения. Идентифицированы 44 основных компонентов эфирного масла и определено их содержание. Отмечено высокое содержание кариофиллена $(24,3 \%)$, $\beta$-пинена $(10,4 \%)$ и бициклосесквифелландрена $(7,4 \%)$.

Ключевые слова: володушка золотистая, эфирное масло, хромато-масс-спектрометрия.

\section{Введение}

Володушка золотистая - Bapleurum aureum - многолетнее травянистое растение с горизонтальным корневищем, несущим в верхней части много почек. Стебли володушки золотистой ветвистые, достигают 1,5 м длины. Нижние листья продолговато-яйцевидные, с черешком. Стеблевые листья сидячие, яйцевидные, с сердцевидным основанием, стеблеобъемлющие или пронзенные. Зонтики крупные, окружены общей обверткой из 3-5 крупных яйцевидных листочков желтого цвета. Растет володушка золотистая на опушках, лесных лугах, по оврагам в негустых хвойных, березовых или осиновых лесах и по берегам рек. Широко распространена в южной части лесной и лесостепной зонах Красноярского края, в горнолесном поясе и на субальпийских лугах Саян и Кузнецкого Алатау [1].

Сибирские ученые, исследовавшие химический состав и лечебные свойства видов володушки, обнаружили в них сапонины, эфирные масла, алкалоиды, дубильные вещества, спирт рибит, витамин С, каротин [2]. Кроме того, у володушек найдены флавонолы (кверцетин, изорамнетин, рутин, изокверцитрин и нарциссин). В официнальной, а ранее в народной медицине виды володушки известны как хорошие желчегонные средства при болезнях печени и желчного пузыря.

Согласно литературным данным в зависимости от содержания в растениях тех или иных биологически активных веществ может происходить избирательное накопление ими некоторых химических элементов $[3,4]$. Поэтому представляло интерес изучение компонентного состава эфирного масла володушки золотистой и ее элементного состава в зависимости от исследуемого органа.

\section{Экспериментальная часть}

Исследуемый материал - надземную часть володушки золотистой - собирали в различных местах

Зыкова Ирина Деменьтьевна - доцент кафедры химии, кандидат технических наук, e-mail: izykova@sfu-kras.ru Ефремов Александр Алексеевич - заведующий лабораторией хроматографических методов анализа центра коллективного пользования, доктор химических наук, професcop, e-mail: AEfremov@sfu-kras.ru произрастания растения в окрестностях г. Красноярска в фазе цветения растения в июле - августе 2011 г. Сырье сушили воздушно-теневым способом.

Эфирное масло получали методом гидропародистилляции $[5,6]$ из воздушно-сухого сырья в тече-

\footnotetext{
* Автор, с которым следует вести переписку.
} 
ние не менее 9 ч до прекращения выделения эфирного масла. Основные физико-химические характеристики - плотность и показатель преломления - определяли с использованием высокоточных приборов Mettler Toledo DE 40 Density Meter и Mettler Toledo RE 40D Refractometer с четырьмя значащими цифрами после запятой при $20^{\circ} \mathrm{C}$.

Хромато-масс-спектрометрический анализ проводили на хроматографе Agilent Technologies 7890 A с квадрупольным масс-спектрометром MSD 5975 С в качестве детектора с использованием 30-метровой кварцевой колонки НР-5 (сополимер 5\%-дифенил - 95\%-диметилсилоксан) с внутренним диаметром 0,25 мм. Температура испарителя $280{ }^{\circ} \mathrm{C}$, температура источника ионов $173{ }^{\circ} \mathrm{C}$, газ-носитель - гелий 1 мл/мин. Температура колонки: $50{ }^{\circ} \mathrm{C}$ (2 мин), 50-270 ${ }^{\circ} \mathrm{C}$ (со скоростью $4{ }^{\circ} \mathrm{C}$ в минуту), изотермический режим при $270{ }^{\circ} \mathrm{C}$ в течение 10 мин.

Содержание компонентов оценивали по площадям пиков, а идентификацию отдельных компонентов производили на основе сравнения времен удерживания и полных масс-спектров с соответствующими данными компонентов эталонных масел и чистых соединений, если они имелись. Для идентификации также использовались данные библиотеки масс-спектров Wiley275 (275 тыс. масс-спектров) [7] и атласа массспектров и линейных индексов удерживания [6]. При полном совпадении масс-спектров и линейных индексов удерживания идентификация считалась окончательной.

Определение зольности разных частей растения проводили в трех параллельных пробах путем озоления измельченных образцов в муфельной печи при температуре 550-600 들 пр доступе воздуха до полного озоления. Полученную золу после охлаждения взвешивали на аналитических весах. Зольность стеблей составила $2,4 \pm 0,1 \%$, зольность листьев - 7,0 $0,2 \%$, зольность цветков $-6,5 \pm 0,2 \%$.

Содержание минеральных элементов определяли с использованием атомно-эмиссионного спектрометра Thermo Scientific iCAP-6500 DUO и программного пакета iTEVA. Данное оборудование и программное обеспечение предназначено для проведения количественного элементного анализа. Спектрометр оборудован системой двойного обзора плазмы (аксиального и радиального), что позволяет определять элементы как в высокой, так и в низкой концентрации. Исследуемые спектральные линии элементов выбирались так, чтобы они не накладывались на линии других элементов, присутствующих в образцах, что может привести к завышению реальных значений концентрации. Итоговая концентрация элементов определялась сравнением интенсивности аналитического сигнала образца с интенсивностью сигнала калибровочного стандарта на длине волны, соответствующей выбранной линии.

\section{Обсуждение результатов}

Эфирное масло из надземной части володушки золотистой, произрастающей в окрестностях г. Красноярска, представляет собой жидкость бирюзового цвета, легче воды. Определены основные физикохимические характеристики масла: показатель преломления - 1,4812, плотность - 0,8416 г/см .

Хромато-масс-спектрометрический анализ позволил установить наличие в эфирном масле володушки золотистой более 40 компонентов. Содержание представленных в таблице компонентов превышает $0,2 \%$ и составляет 95,9\% от цельного масла. Все они являются известными соединениями и легко идентифицируются по масс-спектрам и линейным индексам удерживания.

Представителями ациклических монотерпенов в эфирном масле володушки золотистой являются $\beta$-мирцен, образующийся, согласно работе J. Bohlman с соавторами [8], из (+)-3S-линалилдифосфата путем депротонизации промежуточного карбокатиона, и $\boldsymbol{H}$-нонан. Бициклические монотерпены представлены $\alpha$-пиненом, $\alpha$-фенхеном, лимоненом и $\beta$-пиненом, причем биосинтез последнего доминирует. Содержание лимонена, биосинтез которого происходит через депротонизацию 4S-терпенилкатиона [8], составляет 5,4\%.

Среди ациклических сесквитерпенов установлено присутствие (Е)- $\beta$-фарнезена, (Z,E)- $\alpha$-фарнезена, (Е,Е)- $\alpha$-фарнезена. Среди бициклических сесквитерпенов доминируют кариофиллен $(24,3 \%)$, единственный сесквитерпен, который может образовываться как из транс-, так и из цис-формы неролидилдифосфата [9], и бициклосесквифелландрен (7,4\%). Бициклические сесквитерпены представлены также продуктами превращений гермакрановых предшественников - соединениями групп кадинана, среди которых $\delta$-кадинен присутствует в количестве $1,8 \%$.

Общее количество кислородсодержащих соединений составляет $11,4 \%$. 
Таблица 1. Содержание основных компонентов эфирного масла надземной части володушки золотистой

\begin{tabular}{|c|c|c|c|c|}
\hline № & $\begin{array}{c}\text { Время } \\
\text { удерживания }\end{array}$ & $\begin{array}{c}\text { Линейные индексы } \\
\text { удерживания }\end{array}$ & Компонент & $\begin{array}{c}\text { Содержание, в \% от цель- } \\
\text { ного эфирного масла }\end{array}$ \\
\hline 1 & 6,65 & 900 & $H$-нонан & 1,8 \\
\hline 2 & 7,68 & 932 & $\alpha$-пинен & 2,6 \\
\hline 3 & 8,15 & 945 & $\alpha$-фенхен & 0,2 \\
\hline 4 & 9,11 & 975 & $\beta$-пинен & 10,4 \\
\hline 5 & 9,58 & 991 & $\beta$-мирцен & 1,4 \\
\hline 6 & 10,73 & 1022 & мета-цимол & 0,7 \\
\hline 7 & 10,89 & 1028 & лимонен & 5,4 \\
\hline 8 & 11,08 & 1033 & бензиловый спирт & 0,6 \\
\hline 9 & 11,58 & 1048 & транс- $\beta$-оцимен & 0,2 \\
\hline 10 & 11,95 & 1058 & $\gamma$-терпинен & 0,7 \\
\hline 11 & 13,45 & 1100 & н-ундекан & 2,2 \\
\hline 12 & 16,69 & 1196 & дигидрокарвеол & 0,2 \\
\hline 13 & 20,01 & 1287 & борнилацетат & 2,2 \\
\hline 14 & 20,28 & 1288 & дигидроэдулан & 0,2 \\
\hline 15 & 20,46 & 1300 & н-тридекан & 2,3 \\
\hline 16 & 23,02 & 1328 & $\alpha$-копаен & 0,8 \\
\hline 17 & 24,54 & 1422 & кариофиллен & 24,3 \\
\hline 18 & 24,73 & 1423 & $\beta$-иланген & 0,4 \\
\hline 19 & 24,81 & 1427 & гимачала-2,4-диен & 0,2 \\
\hline 20 & 25,40 & 1432 & селин-4(15),5- диен & 0,4 \\
\hline 21 & 25,53 & 1456 & гумулен & 2,5 \\
\hline 22 & 25,6 & 1458 & (Е)- $\beta$-фарнезен & 2,5 \\
\hline 23 & 25,81 & 1465 & uзис-муурола-4(14),5-диен & 0,5 \\
\hline 24 & 26,14 & 1484 & гермакрен Д & 0,2 \\
\hline 25 & 26,41 & 1494 & бициклосесквифелландрен & 7,4 \\
\hline 26 & 26,78 & 1496 & (Z,E)- $\alpha$-фарнезен & 4,6 \\
\hline 27 & 26,94 & 1500 & $H$-пентадекан & 6,6 \\
\hline 28 & 27,19 & 1510 & 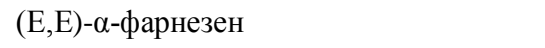 & 2,0 \\
\hline 29 & 27,39 & 1517 & $\gamma$-кадинен & 0,9 \\
\hline 30 & 27,67 & 1527 & $\delta$-кадинен & 1,8 \\
\hline 31 & 27,93 & 1536 & транс-кадина-1,4-диен & 0,4 \\
\hline 32 & 28,09 & 1541 & $\alpha$-кадинен & 0,4 \\
\hline 33 & 28,26 & 1546 & $\alpha$-калакорен & 0,3 \\
\hline 34 & 28,55 & 1554 & (4S)-дигидрокариофиллен-5-он & 0,5 \\
\hline 35 & 28,81 & 1565 & (Е)-неролидол & 0,3 \\
\hline 36 & 29,38 & 1587 & 6(5 $\rightarrow 4)$ абео-кариофилл-8(13)-ен-5-ол & 1,3 \\
\hline 37 & 29,76 & 1598 & салвиол-4(14)-ен-1-он & 0,2 \\
\hline 38 & 30,2 & 1613 & тетрадеканаль & 0,3 \\
\hline 39 & 30,52 & 1625 & (Z)-азарон & 1,7 \\
\hline 40 & 31,09 & 1643 & $\tau$-кадинол & 0,5 \\
\hline 41 & 31,47 & 1658 & $\alpha$-кадинол & 0,5 \\
\hline 42 & 32,19 & 1684 & (Е)-азарон & 2,6 \\
\hline 43 & 32,32 & 1686 & $\alpha$-бисаболол & 0,5 \\
\hline 44 & 32,62 & 1700 & н-гептадекан & 0,2 \\
\hline \multicolumn{4}{|r|}{ ИТОГО } & 95,9 \\
\hline
\end{tabular}

Известно, что физиологическое действие растительных препаратов обусловлено не только биологически активными соединениями растений, но и макро- и микроэлементным составом. Результаты исследования элементного состава володушки золотистой представлены в таблице 2.

Анализ полученных данных показал, что содержание элементов в надземной части володушки золотистой варьирует в зависимости от изучаемого органа. Четко прослеживается направленное распределение элементов по отдельным органам: в листьях больше всего накапливаются В, Ca, Cu, Mn, $\mathrm{Si}$ и $\mathrm{Sr}$, в стеблях $\mathrm{Ba}$, а в цветках - Co, Cd, Ni, Ti, V и Zn. Содержание таких элементов, как Ag, As, Bi, Be, Ga, In, Sb, Se, Sn, составляет не более 0,02 мг/кг. 
Таблица 2. Содержание макро- и микроэлементов в различных органах володушки золотистой, мг/ кг а.с.с.

\begin{tabular}{|c|c|c|c|}
\hline \multirow{2}{*}{ Элемент } & \multicolumn{3}{|c|}{ Содержание, мг/кг } \\
\hline & стебли & листья & цветки \\
\hline $\mathrm{Ag}$ & $<0,02$ & $<0,02$ & $<0,02$ \\
\hline As & $<0,02$ & $<0,02$ & $<0,02$ \\
\hline $\mathrm{B}$ & 9,0 & 21,1 & 19,0 \\
\hline $\mathrm{Ba}$ & 26,0 & 15,5 & 6,1 \\
\hline $\mathrm{Be}$ & $<0,02$ & $<0,02$ & $<0,02$ \\
\hline $\mathrm{Bi}$ & $<0,02$ & $<0,02$ & $<0,02$ \\
\hline $\mathrm{Ca}$ & 12,0 & 25,4 & 12,6 \\
\hline $\mathrm{Co}$ & 0,02 & 0,10 & 0,12 \\
\hline $\mathrm{Cd}$ & 0,002 & 0,004 & 0,006 \\
\hline $\mathrm{Cu}$ & 2,1 & 4,6 & 4,2 \\
\hline $\mathrm{Fe}$ & 15,3 & 67,3 & 67,0 \\
\hline Mn & 27,6 & 112,1 & 65,0 \\
\hline $\mathrm{Ga}$ & $<0,02$ & $<0,02$ & $<0,02$ \\
\hline In & $<0,02$ & $<0,02$ & $<0,02$ \\
\hline $\mathrm{Ni}$ & 2,02 & 5,42 & 7,29 \\
\hline $\mathrm{Pb}$ & 0,13 & 0,42 & 0,42 \\
\hline $\mathrm{Sb}$ & $<0,02$ & $<0,02$ & $<0,02$ \\
\hline $\mathrm{Se}$ & $<0,02$ & $<0,02$ & $<0,02$ \\
\hline $\mathrm{Si}$ & 34,3 & 203,0 & 193,0 \\
\hline $\mathrm{Sn}$ & $<0,02$ & $<0,02$ & $<0,02$ \\
\hline $\mathrm{Sr}$ & 26,4 & 44,4 & 24,0 \\
\hline $\mathrm{Ti}$ & 1,2 & 2,5 & 3,4 \\
\hline $\mathrm{V}$ & 0,04 & 0,12 & 0,15 \\
\hline $\mathrm{Zn}$ & 4,8 & 14,0 & 15,1 \\
\hline
\end{tabular}

Показано, что растение испытывает дефицит меди $(\mathrm{Cu})$ и цинка $(\mathrm{Zn})$. Содержание этих элементов ниже достаточного уровня: 5-30 мг/кг для $\mathrm{Cu}$ и 27-150 мг/кг для $\mathrm{Zn} \mathrm{[10],} \mathrm{что} \mathrm{может} \mathrm{свидетельствовать}$ о недостатке подвижных форм этих элементов в почве. Следует отметить, что максимальная концентрация $\mathrm{Zn}$ характерна для цветков, что вполне объяснимо биологическим значением этого элемента, участвующего в процессе формирования генеративных органов.

Железо (Fe) и марганец (Mn) тесно взаимосвязаны в метаболических процессах, и для нормального развития растения их соотношение должно быть в пределах 1,5-2,5 [10]. Соотношение этих элементов находится в норме для листьев растения $(1,7)$ и ниже нормы для стеблей и цветков $(0,6$ и 1,0, соответственно).

Кремний и стронций концентрируются в листьях володушки, а никель (Ni) - в цветках. Вероятно, это объясняется необходимостью никеля для завершения жизненного цикла растений и развития жизнеспособных семян [11].

Учитывая разнообразное применение исследуемого растения в народной медицине, мы проанализировали содержание свинца $(\mathrm{Pb})$ и кадмия $(\mathrm{Cd})$ как токсичных элементов, регламентируемых для пищевых продуктов. Установлено, что концентрация $\mathrm{Pb}$ и $\mathrm{Cd}$ во всех органах володушки золотистой не превышает ПДК, принятые для чая [12].

\section{Заключение}

Таким образом, в результате выполненной работы методом хромато-масс-спектрометрии установлен качественный и количественный составы эфирного масла, полученного из надземной части володушки золотистой, произрастающей в окрестностях г. Красноярска. Среди основных компонентов отмечено высокое содержание кариофиллена $(24,3 \%), \beta$-пинена $(10,4 \%)$ и бициклосесквифелландрена $(7,4 \%)$.

Результаты изучения элементного состава володушки золотистой позволяют сделать вывод о безопасности применения ее лекарственных форм в народной медицине.

\section{Список литературы}

1. Махов А.А. Зеленая аптека. Красноярск, 1993. 528 с.

2. Израильсон В.Ф. К интродукции представителей Bapleurum aureum (L.) // Перспективные полезные растения природной флоры Сибири. Новосибирск, 1973. С. 92-100. 
3. Ноздрюхина Л.Р., Гринкевич Н.И. Нарушения микроэлементного обмена и пути его коррекции. М., 1980. 280 с.

4. Мартынов A.M., Чупарина Е.В. Фиалка песчаная (Viola Arenaria Dc.) - новый источник макро- и микроэлементов // Сибирский медицинский журнал. 2008. №3. С. 98-99.

5. Ткачев А.В. Исследование летучих веществ растений. Новосибирск, 2008. 969 с.

6. Щипицина О.С., Ефремов А.А. Компонентный состав эфирного масла различных вегетативных частей дудника лекарственного Сибирского региона // Химия растительного сырья. 2010. №4. С. 115-119.

7. McLafferty F.W. The Wiley. NBS Registry of Mass Spectral Data; Wiley. London, 1989. 563 p.

8. Bohlman J., Steele C.L., Croteau R. Monoterpene Synthases from Grand Fir (Abies grandis) cDNA isolation,characterization, and functional expression of myrcene synthase, (-)-(4S)-limonene synthase, and (-)-(4S)limonene synthase, and (-)-(1S,5S)-pinene synthase // J. Biol. Chem. 1997. Vol. 272, N35. Pp. 21784-21792.

9. Steele C.L. Sesquiterpene synthases from grand fir (Abies grandis) // J. Biol. Chem. 1998. Vol. 273, N4. Pp. $2078-2089$.

10. Кабата-Пендиас А., Пендиас Х. Микроэлементы в почвах и растениях. М., 1989. 439 с.

11. Brown P.H., Welch R.M., Cary E.E. Nickel: a micronutrient essential for higher plats // Plant Physiol. 1987. Vol. 85. Pp. 801-803.

12. Санитарные правила и нормы 2.3.2.1078-01. Гигиенические требования к безопасности и пищевой ценности пищевых продуктов. Продовольственное сырье и пищевые продукты. М., 2002.

Поступило в редакичию 25 февраля 2012 2.

После переработки 30 марта 2013 г.

Zykova I.D. , Efremov A.A. THE STUDY OF CHEMICAL COMPOSITION OF ESSENTIAL OIL FROM ABOVEGROUND PARTS OF BAPLEURUM AUREUM

Siberian Federal University, st. Svobodnyi, 79, Krasnoyarsk, 660041 (Russia), e-mail: izykova@sfu-kras.ru

By means of the method GC-MS was investigated the component composition of essential oil from Bapleurum aureum. 4 major components of essential oils and their contents were identified. High levels of caryophyllene $(24,3 \%), \beta$-pinene $(10,4 \%)$ and bicyclosesquiphellandrene $(7,4 \%)$ were noted.

Keywoods: Bapleurum aureum, componental composition, method GC-MS.

\section{References}

1. Makhov A.A. Zelenaia apteka. [Green Pharmacy]. Krasnoyarsk, 1993, 528 p. (in Russ.).

2. Izrail'son V.F. Perspektivnye poleznye rasteniia prirodnoi flory Sibiri. [Prospective useful plants of the natural flora of Siberia]. Novosibirsk, 1973, pp. 92-100. (in Russ.).

3. Nozdriukhina L.R., Grinkevich N.I. Narusheniia mikroelementnogo obmena i puti ego korrektsii. [Violations of trace element metabolism and the way of its correction]. Moscow, 1980, 280 p. (in Russ.).

4. Martynov A.M., Chuparina E.V. Sibirskii meditsinskii zhurnal, 2008, no. 3, pp. 98-99. (in Russ.).

\footnotetext{
* Corresponding author.
} 
5. Tkachev A.V. Issledovanie letuchikh veshchestv rastenii. [The study of plant volatiles]. Novosibirsk, 2008,969 p. (in Russ.).

6. Shchipitsina O.S., Efremov A.A. Khimiia rastitel'nogo syr'ia, 2010, no. 4, pp. 115-119. (in Russ.).

7. McLafferty F.W. The Wiley. NBS Registry of Mass Spectral Data, Wiley. London, 1989. 563 p.

8. Bohlman J., Steele C.L., Croteau R. J. Biol. Chem., 1997, vol. 272, no. 35, pp. 21784-21792.

9. Steele C.L. J. Biol. Chem., 1998, vol. 273, no. 4, pp. 2078-2089.

10. Kabata-Pendias A., Pendias Kh. Mikroelementy v pochvakh i rasteniiakh. [Trace elements in soils and plants]. Moscow, 1989, 439 p. (in Russ.).

11. Brown P.H., Welch R.M., Cary E.E. Plant Physiol., 1987, vol. 85, pp. 801-803.

12. Sanitarnye pravila $i$ normy 2.3.2.1078-01. Gigienicheskie trebovaniia $k$ bezopasnosti $i$ pishchevoi tsennosti pishchevykh produktov. Prodovol'stvennoe syr'e i pishchevye produkty. [Sanitary rules and norms 2.3.2.1078-01. Hygiene requirements for the safety and nutritional value of foods. Food raw materials and food products]. Moscow, 2002. (in Russ.).

Received February 25, 2012

Revised March 30, 2013 